\title{
Metataxonomic and immunological analysis of milk from ewes with or without a history of mastitis
}

\author{
Irma Castro, ${ }^{1}$ Claudio Alba, ${ }^{2}$ Marina Aparicio, ${ }^{1}$ Rebeca Arroyo, ${ }^{1}$ Lorena Jiménez, ${ }^{3}$ Leónides Fernández, ${ }^{2}$ \\ Ramón Arias, ${ }^{3 *}$ and Juan Miguel Rodríguez ${ }^{1 *}$ \\ ${ }^{1}$ Department of Nutrition and Food Science, Complutense University of Madrid, 28040 Madrid, Spain \\ ${ }^{2}$ Departmental Section of Food Technology, Complutense University of Madrid, 28040 Madrid, Spain \\ ${ }^{3}$ CERSYRA, Regional Institute of Agrifood and Forestry Research and Development of Castilla La Mancha, 13300 Valdepeñas, Spain
}

\section{ABSTRACT}

Mastitis is a highly prevalent condition that has a great impact on milk production and animal welfare, and often requires substantial management efforts. For this reason, it is generally considered an important threat to the dairy industry. Many microbial, host, and environmental factors can protect against, predispose to, or influence the development of mastitis. The objective of this work was to characterize the milk microbiota of Manchega ewes, and to compare samples from animals with and without a history of mastitis. We analyzed milk samples from 36 ewes belonging to 2 different farms (18 ewes from each farm) using culturedependent and culture-independent techniques. We also analyzed several immune compounds to investigate associations of mastitis with 3 main variables: farm; history of mastitis or no mastitis; and parity number. Both culture-dependent and culture-independent techniques showed that ewe milk harbored a site-specific complex microbiota and microbiome. Staphylococcus epidermidis was the main species driving the difference between farm A (where it was the dominant species) and B (where it was not). In contrast, samples from farm B were characterized by the presence of a wide spectrum of other coagulase-negative staphylococci. Some of these species have already been associated with subclinical intramammary infections in ruminants. Of the 10 immune compounds assayed in this study, 3 were related to a history of mastitis [IL- 8, IFN- $\gamma$, and IFN-gamma-induced protein 10 (IP-10)]. Increases in IL-8 concentrations in milk seemed to be a feature of subclinical mastitis in sheep, and in this study, this immune factor was detected only in samples from ewes with some episodes of mastitis and from the group with the highest somatic cell count. We also observed a posi-

Received January 30, 2019

Accepted June 18, 2019.

*Corresponding authors: rarias@jccm.es and jmrodrig@vet.ucm.es tive correlation between the samples with the highest somatic cell count and IFN- $\gamma$ and IP-10 levels. Our results suggest that these 3 compounds could be used as biomarkers for the negative selection of mastitis-prone animals, particularly when somatic cell count is very high.

Key words: ewe, milk, mastitis, microbiota, microbiome, immunological analysis

\section{INTRODUCTION}

The health of mammary glands in dairy ruminants is essential for the production of high-quality milk, so it has strong economic and social effects in rural settings where the production of milk, cheese, and other dairy products is important for the local economy (Gonzalo et al., 2002; Ezzat Alnakip et al., 2014). Mastitis is broadly defined as an inflammation of the mammary gland, and it most often results from bacterial infection (Contreras and Rodriguez, 2011). Mastitis is highly prevalent; it has a strong effect on the structure and function of the mammary gland, milk production and quality, and animal welfare, and it often requires substantial management efforts (Akers and Nickerson, 2011; EFSA, 2014; Ezzat Alnakip et al., 2014). As a consequence, it is generally considered an important threat to the dairy industry.

Interestingly, some animals may be mastitis susceptible and some mastitis resistant, even in the same herd (Bonnefont et al., 2011). Research has contributed to our understanding of risk factors, including animals' genetic susceptibility to infections (Gelasakis et al., 2015). In fact, many microbial, host, and environmental factors can protect against, predispose to, or influence the development of mastitis (Fernández et al., 2014; Derakhshani et al., 2018; Hughes and Watson, 2018). In addition, some recent studies have suggested that the mammary gland harbors a site-specific microbiota (Fernández et al., 2013; Pang et al., 2018), and that alterations of this mammary-related microbiota (so- 
called mammary dysbiosis) can predispose or lead to mastitis (Fernández et al., 2014; Sam Ma et al., 2015; Qiao et al., 2015; Patel et al., 2017). The bacterial microbiota in the mammary gland of cows has repeatedly been reported to have a protective effect against mastitis (Linde et al., 1980; Matthews et al., 1990; Lam et al., 1997). Similarly, the bacterial microbiota in the teat ducts of ewes can protect against mastitis but, under certain circumstances, some of those bacteria can behave as opportunistic pathogens and cause mastitis (Fragkou et al., 2007). On the other hand, the mammary gland is protected by several innate and acquired immunity mechanisms that prevent microbial proliferation (Sordillo and Streicher, 2002), but increases in milk SCC during mastitis are also associated with decreases in milk production (Arias et al., 2012).

So far, most microbiome and immunological studies of ruminant milk have been carried in cows; less is known about small ruminants. The objective of this work was to characterize the milk microbiota (cultivable bacteria) and microbiome (bacterial diversity as assessed by using culture-independent methods) of Manchega ewes, and to compare samples from animals with and without a history of mastitis. For this purpose, we collected milk samples from 2 different farms and analyzed them using culture-dependent and culture-independent techniques. We also analyzed several immune compounds in the same milk samples.

\section{MATERIALS AND METHODS}

\section{Animals and Sampling}

All animals were treated in strict accordance with the guidelines of the European Directive 2010/63/UE on the protection of animals used for scientific purposes. The study was approved by Ethical Committee on Animal Experimentation of Universidad Complutense de Madrid (Spain), under protocol 24/17.

We analyzed milk samples from a total of 36 Manchega ewes from 2 farms (18 ewes from each farm). The distance between farms was approximately $15 \mathrm{~km}$. Ewes have 4 parities per year, and complete weaning is accomplished at $30 \mathrm{~d}$ postpartum. In both farms, the milking groups were composed of 200 ewes, and the milking parlor contained $18 \times 2$ highline milking places operating at vacuum levels of $40 \mathrm{kPa}$ at 180 pulses/ min. A complete milking included intermediate massage and post-milking disinfection of teats after each milking, alternating between iodine- and chlorhexidinebased disinfectants. Straw bedding was used in both farms, and milking ewes were fed a TMR $(1 \mathrm{~kg} / \mathrm{L}$ of produced milk).
Both farms were included in the Manchega sheep selection scheme (ESROM) and submitted data to official milk recordings, following the AT4 method of the International Committee for Animal Recording (https: //www.icar.org/Guidelines/16-Dairy-Sheep-and-Goats .pdf), including the SCC values of all ewes during all lactation periods. Since 2004, both farms have also been part of the raw milk quality improvement program of the National Association of Selected Sheep Breeders of Manchega Breed (AGRAMA) and, as a result, have recorded other parameters related to the mammary health of each ewe [e.g., udder examination, California Mastitis Test (CMT) results], at least once in each lactation period.

All ewes from both farms were individually identified with electronic rumen boluses and were sampled at 60 to $75 \mathrm{~d}$ postpartum in the same season (winter) and at the same time of day (early in the morning). All ewes had undergone a previous milk control at $45 \mathrm{~d}$ postpartum, and the SCC values from this previous control were taken into account when selecting animals for the present study. At sampling time, the general sanitary status of each animal was assessed, including examination of the udders, visual inspection of the first ejected milk, and a CMT. Only ewes with no clinical signs of mastitis and a negative result on the CMT were included in the study. Before sampling, udders were washed and disinfected with $70 \%$ alcohol. For each ewe, all milk from a complete milking was collected in a sterile container and cooled immediately at $<4^{\circ} \mathrm{C}$; after homogenization, milk was aliquoted (100-mL fractions) in sterile Falcon tubes. One of the aliquots was used for culture-dependent analysis, one for DNA extraction and microbiome analysis, and a third for immunological profiling. The 2 first aliquots were kept frozen at $-80^{\circ} \mathrm{C}$ and the third was stored at $-20^{\circ} \mathrm{C}$.

Although none of the ewes included in this study displayed clinical signs of mastitis and their milk was CMT-negative at sampling time, we classified the samples into 3 groups according to the ewes' history of mastitis and SCC: no history of mastitis and SCC $<250,000$ cells/mL; previous episodes of mastitis and SCC $>250,000$ to $<1,000,000$ cells $/ \mathrm{mL}$; and previous episodes of mastitis and SCC $>1,000,000$ cells $/ \mathrm{mL}$ (Table 1). We also classified the animals into 3 groups according to their number of parities: $2-3 ; 4-6$; and $7-9$ (Table 1). Samples were stored at $-80^{\circ} \mathrm{C}$.

\section{Milk Cultures}

Aliquots of serial decimal dilutions of the milk samples in sterile peptone water were plated in triplicate onto Columbia Nalidixic Acid (CNA; a medium par- 
ticularly suitable for isolation of streptococci, staphylococci, enterococci, corynebacteria, and related grampositive bacteria; BioMérieux, Marcy-l'Étoile, France), Violet Red Bile Agar (VRBA; a medium for the isolation of enterobacteria and related gram-negative bacteria; Oxoid, Basingstoke, UK), and De Man, Rogosa, and Sharpe (MRS; a medium for the isolation of lactic acid bacteria; Oxoid), supplied with L-cysteine (MRS-Cys) agar plates. The VRBA and CNA plates were incubated in aerobiosis at $37^{\circ} \mathrm{C}$ for 24 and $48 \mathrm{~h}$, respectively; the MRS-Cys plates were incubated anaerobically ( $85 \%$ nitrogen, $10 \%$ hydrogen, $5 \%$ carbon dioxide) in an anaerobic workstation (MINI-MACS; DW Scientific, Shipley, UK) at $37^{\circ} \mathrm{C}$ for $48 \mathrm{~h}$. After incubation, counts in each growth medium were recorded and at least 1 representative of each colony morphology was selected from the agar plates. The isolates were identified by MALDI-TOF mass spectrometry using a Vitek-MS instrument (BioMérieux), following the protocol described by Jiménez et al. (2015). For each isolate, a mean spectrum was constructed with at least $50 \mathrm{~m} / z$ spectra profiles and compared with the spectra in the Myla database (BioMérieux). Identification was defined as a 99 to $100 \%$ match to the species-specific $\mathrm{m} / \mathrm{z}$ values in the database.

\section{DNA Extraction from the Milk Samples}

All samples were centrifuged for $15 \mathrm{~min}$ at 11,000 $\times g$ at $4^{\circ} \mathrm{C}$. Extraction of DNA from the pellets was performed following the protocol of the QIAamp DNA Stool Mini Kit (Qiagen, Hilden, Germany) as described by the manufacturer (QIAamp Fast DNA Stool Mini Handbook; https://www.qiagen.com) with the following modifications: the samples were mechanically lysed using FastPrep Fp120 (Thermo Scientific, Waltham,
MA) and glass bead matrix tubes $(3$ cycles $\times 60 \mathrm{~s}$, speed 6) in step 4. After centrifugation, the RNA from the supernatant was removed using ribonuclease A (10 $\mathrm{mg} / \mathrm{mL}$ ) and incubated $15 \mathrm{~min}$ at $37^{\circ} \mathrm{C}$. The protein fraction was eliminated with a proteinase $\mathrm{K}$ treatment at $70^{\circ} \mathrm{C}$ for $10 \mathrm{~min}$. Extracted DNA was eluted in $20 \mu \mathrm{L}$ of nuclease-free water and stored at $-20^{\circ} \mathrm{C}$ until further analysis. The DNA concentration was estimated using an ND-1000 UV spectrophotometer (Nano Drop Technologies, Wilmington, DE).

\section{PCR Amplification and Sequencing}

A dual-barcoded 2-step PCR reaction was conducted to amplify a fragment of the V3-V4 hypervariable region of the bacterial $16 \mathrm{~S}$ ribosomal RNA gene. Equimolar concentrations of the universal primers S-D-Bact-0341-b-S-17 (ACACTGACGACATGGTTCTACACCTACGGGNGGCWGCAG) and S-D-Bact0785-a-A-21 (TACGGTAGCAGAGACTTGGTCTGACTACHVGGGTATCTAATCC) were used as previously described (Klindworth et al., 2013), generating amplicons of approximately $464 \mathrm{bp}$ from the V3-V4 hypervariable region. The primers were synthesized by Isogen Life Sciences (Castelldefels, Spain). Barcodes used for Illumina sequencing were appended to $3^{\prime}$ and $5^{\prime}$ terminal ends of the PCR amplicons to allow for the separation of forward and reverse sequences. A 2100 Bioanalyzer (Agilent Technologies, Santa Clara, CA) was used to determine the concentration of each sample. Two negative control blanks, in which the sample was replaced by the same volume of nuclease-free moleculargrade water (Sigma-Aldrich, St Louis, MO), previously exposed to the sample containers, were subject to all steps of the DNA extraction and purification procedure described above. The concentration of DNA in the 2

Table 1. Main characteristics and classifications of the ewes (codes) included in this study

\begin{tabular}{|c|c|c|c|c|}
\hline \multirow[b]{2}{*}{ Farm } & \multirow{2}{*}{$\begin{array}{c}\text { No history of mastitis } \\
\begin{array}{c}\text { SCC }<250,000 \\
\text { cells } / \mathrm{mL}\end{array}\end{array}$} & \multicolumn{2}{|c|}{ History of mastitis } & \multirow[b]{2}{*}{$\begin{array}{l}\text { No. of } \\
\text { parities }\end{array}$} \\
\hline & & $\begin{array}{l}\mathrm{SCC}>250,000 \text { and } \\
<1,000,000 \text { cells } / \mathrm{mL}\end{array}$ & $\begin{array}{c}\mathrm{SCC}>1,000,000 \\
\text { cells } / \mathrm{mL}\end{array}$ & \\
\hline \multirow[t]{7}{*}{ A } & A14 & A8 & A5 & $2-3$ \\
\hline & $\mathrm{A} 6$ & $\mathrm{~A} 12$ & A9 & \\
\hline & A17 & A18 & A16 & $4-6$ \\
\hline & $\mathrm{A} 1$ & A13 & - & \\
\hline & - & A10 & - & \\
\hline & A7 & A3 & A11 & $7-9$ \\
\hline & A4 & A15 & A2 & \\
\hline \multirow[t]{6}{*}{ B } & B1 & B7 & B13 & $2-3$ \\
\hline & B2 & B8 & B14 & \\
\hline & B3 & B9 & B15 & $4-6$ \\
\hline & B4 & B10 & B16 & \\
\hline & B5 & B11 & B17 & $7-9$ \\
\hline & B6 & B12 & B18 & \\
\hline
\end{tabular}


blank preparations was approximately $0.01 \mathrm{ng} / \mu \mathrm{L}$ and the concentration obtained from the biological samples was at least $149.2 \mathrm{ng} / \mu \mathrm{L}$. In addition, we detected no amplification from the blank samples after the first PCR, so the 2 blank controls were not submitted to sequencing.

Barcoded PCR products from all samples were pooled at approximately equimolar DNA concentrations and run on a preparative agarose gel. The correctsized band was excised and purified using a QIAEX II Gel Extraction Kit (Qiagen) and then quantified with PicoGreen (BMG Labtech, Jena, Germany). Finally, 1 aliquot of pooled, purified, barcoded DNA amplicons was sequenced using the Illumina MiSeq pair-end protocol (Illumina Inc., San Diego, CA) at the Scientific Park of Madrid (Spain). The sequences analyzed for this study are available in the BioSample database of the National Center for Biotechnology Information (BioProject ID PRJNA517581).

The amplified fragments and results were taxonomically analyzed using the Illumina software (version 2.6.2.3) according to the manufacturer's guidelines and pipelines (https://www.illumina.com). The resulting high-quality reads were assembled and classified taxonomically into operational taxonomic units (OTU) by comparing them with the Illumina-curated version using a Bayesian classification method and a level of similarity of at least $97 \%$.

\section{Immunological Analysis}

The concentration of 10 ovine cytokines, including interferon-inducible protein (IP)-10, IP-8, chemokine (C-X-C motif) ligand 9 (CXCL9), decorin, secreted frizzled-related protein 3, IFN- $\gamma$, IL-17A, IL-21, TNF- $\alpha$, and vascular endothelial growth factor A, were measured using the glass-slide-based Quantibody Ovine Cytokine Array (RayBiotech, Peachtree Corners, GA). All determinations were carried out following the manufacturer's protocol (https://www.raybiotech.com/ovine -sheep-protein-array-q1), and standard curves were performed for each analyte. Before analysis, the fatty layer and somatic cells of the samples were removed by centrifugation at $11,000 \times g$ for $15 \mathrm{~min}$ at $4^{\circ} \mathrm{C}$ to avoid interference during the immunoassays.

\section{Statistical and Bioinformatics Analysis}

Microbiological data (recorded as $\mathrm{cfu} / \mathrm{mL}$ of milk) were transformed to logarithmic values before statistical analysis. The concentrations, both of microorganisms and immunological compounds, were expressed as median and interquartile ranges. We analyzed the normality of data distribution using the Shapiro-Wilks test, evidencing non-normal distribution for all tested variables $(P<0.05)$. Accordingly, we used nonparametric statistical analyses. Differences in the detection frequencies of the immunological compounds were analyzed using the Fisher test. We used the Kruskal-Wallis test to evaluate the differences between bacterial counts and also for cytokine concentrations. Differences were considered significant at $P<0.05$ for all analyses. The R-project software version 3.5.1 (https://www.r -project.org/) was used to perform these analyses.

Bioinformatics analysis was also conducted combining R (v 3.2.3), QIIME pipelines ( $v$ 1.8.0; Caporaso et al., 2010), and Calypso (v 8.84; Zakrzewski et al., 2017). Estimates of intrasample diversity were made at a rarefaction depth of 100,000 reads per sample. Alpha diversity was assessed with the Shannon diversity index, which considers the number and evenness of microbial species, using ANOVA. The richness distribution level (rarefaction curves) was analyzed using the Montecarlo test. Beta diversity was studied using principal coordinates analysis (PCoA) to visually display patterns of $\beta$ diversity through a distance matrix containing a dissimilarity value for each pairwise sample comparison. For quantitative and qualitative analyses, we used the Bray-Curtis and binary Jaccard indices, respectively. Permutational multivariate ANOVA (PERMANOVA) with 999 permutations revealed statistically significant differences $(P<0.05)$. Spearman's rank correlation matrix was performed to show relations between genera. Differences in sample group genera were compared by using the Wilcoxon rank test for variables with 2 groups, or the Kruskal-Wallis test for variables with more than 2 groups.

\section{RESULTS}

\section{Culture-Dependent Analysis}

Bacterial growth in the media used in this study was observed in 28 of the 36 milk samples. Among the samples without detectable growth $(\mathrm{n}=8), 4(2$ from each farm) came from ewes without a history of mastitis (SCC $<250,000$ cells $/ \mathrm{mL}$; Table 2 ). The remaining 4 samples without growth were obtained from animals from farm A (3 with SCC >250,000 to $<1,000,000$ cells $/ \mathrm{mL}$ and 1 with $\mathrm{SCC}>1,000,000$ cell $/ \mathrm{mL})$. The mean total bacterial count in the milk samples with detectable growth was $4.00 \log _{10} \mathrm{cfu} / \mathrm{mL}$, with values ranging from 1.00 to $4.89 \log _{10} \mathrm{cfu} / \mathrm{mL}$. A total of 68 isolates were identified at the genus or species level (Table 2). The mean number of isolates per sample was 2.43 (considering only the 28 samples in which growth 
Table 2. Relative frequency, median, and interquartile range (IQR) of the bacterial genera and species in the milk samples

\begin{tabular}{lccc}
\hline Microorganism & $\begin{array}{c}\mathrm{N}^{1} \\
(\%)\end{array}$ & $\begin{array}{c}\text { Median (IQR), } \\
\log _{10} \mathrm{cfu} / \mathrm{mL}\end{array}$ & $\begin{array}{c}\text { Range } \\
\left(\log _{10} \mathrm{cfu} / \mathrm{mL}\right)\end{array}$ \\
\hline Staphylococcus spp. ${ }^{2}$ & $19(68)$ & $1.70(1.30-2.32)$ & $1.00-4.48$ \\
Staphylococcus epidermidis & $12(43)$ & $2.11(1.44-3.95)$ & $1.00-4.89$ \\
Corynebacterium spp. & $7(25)$ & $2.40(1.95-3.08)$ & $1.30-3.60$ \\
Aerococcus viridans & $3(11)$ & $1.30(1.18-2.23)$ & $1.00-2.51$ \\
Bacillus spp. & $3(11)$ & 1.00 & 1.00 \\
Enterococcus hirae & $3(11)$ & $1.48(1.30-1.98)$ & $1.00-2.20$ \\
Micrococcus luteus/lylae & $3(11)$ & $1.85(1.60-2.18)$ & $1.00-2.36$ \\
Pseudomona aeruginosa & $2(7)$ & $2.77(2.50-2.93)$ & $1.70-3.05$ \\
Streptococcus spp. & $2(7)$ & $2.70(2.41-2.88)$ & $1.00-3.00$ \\
Candida spp. & $1(4)$ & 1.60 & 1.60 \\
Clavibacter michiganensis & $1(4)$ & 3.11 & 1.60 \\
Rhodococcus equi & $1(4)$ & 1.60 & 1.90 \\
Sphingobacterium spiritivorum & $1(4)$ & 1.90 & \\
${ }^{1}$ Number of samples with the species present (total samples, $\left.\mathrm{n}=28\right)$. & \\
${ }^{2}$ Including Staph. epidermidis, Staph. auricularis, Staph. equorum, Staph. felis, Staph. haemolyticus, Staph. \\
hominis, Staph. schleiferi, and Staph. warneri. & & \\
${ }^{3}$ Including Bacillus licheniformis and Bacillus pumilus. &
\end{tabular}

was observed) or 1.89 (considering all 36 samples cultured in this work). However, 11 of the 36 milk samples had more than 2 different bacterial isolates.

Staphylococcus was the genus found in the highest percentage of samples $(68 \%)$ and included the species Staph. epidermidis, Staph. auricularis, Staph. equorum, Staph. felis, Staph. haemolyticus, Staph. hominis, Staph. schleiferi, and Staph. warneri. Staphylococcus epidermidis was the species with the highest frequency of detection $(43 \%)$ among the samples, and its median count was $2.11 \log _{10} \mathrm{cfu} / \mathrm{mL}$. Corynebacterium was the second genus in order of frequency of detection (25\%), and its median count was $2.40 \log _{10} \mathrm{cfu} / \mathrm{mL}$. We isolated the species Aerococcus viridans, Enterococcus hirae, and Micrococcus luteus, and the genus Bacillus (including Bacillus licheniformis and Bacillus pumilus) from approximately $10 \%$ of samples, followed by the species Pseudomonas aeruginosa and the genus Streptococcus spp., which were detected in $7 \%$ of the samples. Finally, we isolated Candida spp., Clavibacter michiganensis, Rhodococcus equi, and Sphingobacterium spiritivorum, each from a different single sample.

We isolated $A$. viridans, $R$. equi, and B. licheniformis exclusively from samples from ewes without a history of mastitis. In contrast, we isolated B. pumilus, C. michiganensis, E. hirae, P. aeruginosa, Staph. felis, Staph. haemolyticus, Staph. equorum, Staph. schleiferi, Staph. warneri, Sphingobacterium spiritivorum, Candida spp., and Corynebacterium spp. only from samples from ewes with a history of mastitis. We found Staph. auricularis, Staph. epidermidis, and M. luteus in both groups.

We found $A$. viridans, B. licheniformis, $R$. equi, Staph. felis, and Streptococcus spp. only in samples from farm A. We found B. pumilus, C. michiganensis, Staph. equorum, Staph. haemolyticus, Staph. hominis, Staph. schleiferi, Staph. warneri, P. aeruginosa, and Candida spp. only in samples from farm B. We found Corynebacterium spp., E. hirae, M. luteus, Staph. auricularis, and Staph. epidermidis in samples from both farms.

The mean total bacterial counts of samples from ewes without a history of mastitis was $3.04 \log _{10} \mathrm{cfu} / \mathrm{mL}$ and of samples from ewes with a history of mastitis was 3.85 $\log _{10} \mathrm{cfu} / \mathrm{mL}$; the values were not statistically different $(P=0.890)$. We detected a trend between total bacterial count and SCC $(P=0.084)$. Finally, the median total bacterial counts for farm A and farm B were 3.65 $\log _{10} \mathrm{cfu} / \mathrm{mL}$ and $3.75 \log _{10} \mathrm{cfu} / \mathrm{mL}$, respectively; again, values were not statistically different $(P=0.365)$.

\section{Microbiome Analysis}

We obtained a total of 5,641,300 high-quality-filtered sequences from the 36 samples analyzed in this study, and the number of sequences ranged from 90,800 to 203,797 per sample (median: 155,972; mean \pm SD: $156,702 \pm 26,783)$. We detected the following phyla in the 2 farms analyzed in this study: Proteobacteria, Firmicutes, Fusobacteria, Actinobacteria, Bacteroidetes, and Cyanobacteria.

Initially, we attempted to identify potential differences in the microbiome profiles between animals depending on the farm. At the OTU level, the PCoA plots of the Bray-Curtis distance matrix (relative abundance) revealed that most of the samples clustered according to farm, and subsequent analysis of similarity (PERMANOVA) revealed that the difference between the 2 groups was statistically significant $(P=0.001)$. 
The 2-dimensional PCoA of the binary Jaccard distance matrix (presence or absence) also revealed that the samples clustered according to farm (Supplemental Figure S1; https://doi.org/10.3168/jds.2019-16403). In this case, analysis of similarity (PERMANOVA) also revealed that the difference between groups was statistically significant $(P=0.003$; Supplemental Figure S1). Similarly, the relative abundance of the 20 most abundant genera (total sum normalization) also revealed a clear separation of animals by farm (Figure 1; Supplemental Table S1; https://doi.org/10.3168/jds .2019-16403). At the genus level, we found statistically significant differences between farms in relation to the weight of the genera Staphylococcus $(P=0.002)$, Paenibacillus $(P=0.004)$, and Geobacillus $(P=0.004)$, which were more abundant on farm A than on farm B (Supplemental Table S1; https://doi.org/10.3168/ jds.2019-16403). We measured the biodiversity of the samples using the Shannon index and found that the diversity was significantly higher in samples from farm B than farm A $(P=0.001$; Supplemental Figure S2; https://doi.org/10.3168/jds.2019-16403).
Because of the significant differences in the microbiome compositions of the samples depending on the farm, we carried out subsequent microbiome analyses to assess the effect of a history of mastitis independently for each farm. The PCoA plots of bacterial profiles (at the OTU level) based on Jaccard's coefficient for binary data (presence or absence) and on Bray-Curtis similarity analysis of the milk samples from farm A indicated that a history of mastitis did not affect the clustering of bacterial profiles $(P=0.606$ and $P=$ 0.581 , respectively) (Figure 2). The same lack of clustering can be seen in the heat map showing the relative abundance of the most abundant bacterial genera ( $\mathrm{x}$ axis) detected in milk samples from farm A (Figure 3). The Spearman's rank correlation matrix of the major bacterial groups (present in $>50 \%$ of the samples with a relative abundance $>0.1 \%$ ) in the same milk samples revealed a positive correlation between Staphylococcus and Paenibacillus, and a negative correlation between Staphylococcus and "unclassified genera" (those that were not present in $>50 \%$ of the samples or whose relative abundance was $<0.1 \%$; Figure 3 ).

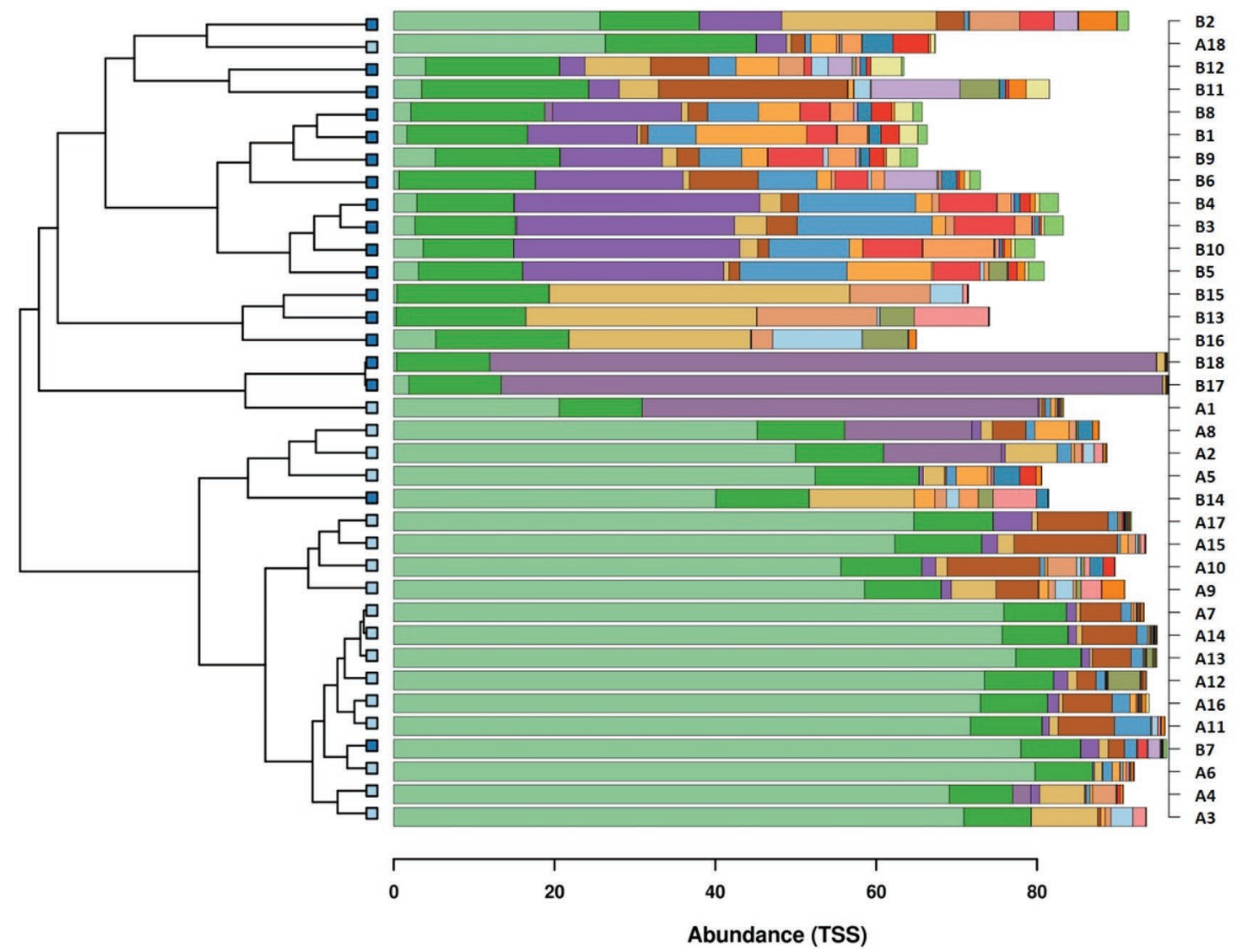

\begin{tabular}{|l|}
\hline Groups: \\
$\square$ A \\
$\square$ B \\
Features: \\
$\square$ Serratia \\
$\square$ Bacillus \\
$\square$ Sphingomonas \\
$\square$ Alkaliphilus \\
$\square$ Clostridium \\
$\square$ Dechloromonas \\
$\square$ Calothrix \\
$\square$ Listeria \\
$\square$ Jeotgalicoccus \\
$\square$ Bradyrhizobium \\
$\square$ Escherichia \\
$\square$ Cupriavidus \\
$\square$ Corynebacterium \\
$\square$ Streptococcus \\
$\square$ Lactobacillus \\
$\square$ Methylobacterium \\
$\square$ Bifidobacterium \\
$\square$ Mannheimia \\
$\square$ Unclassified_genera \\
$\square$ Staphylococcus \\
\hline
\end{tabular}

Figure 1. Comparison of the relative abundance of the 20 most abundant genera (TSS = total sum scaling normalization) in the milk samples analyzed in this study. The dendrogram is based on similarity in genera between the samples. The "hclust" method was used to compute hierarchical clustering. 
A
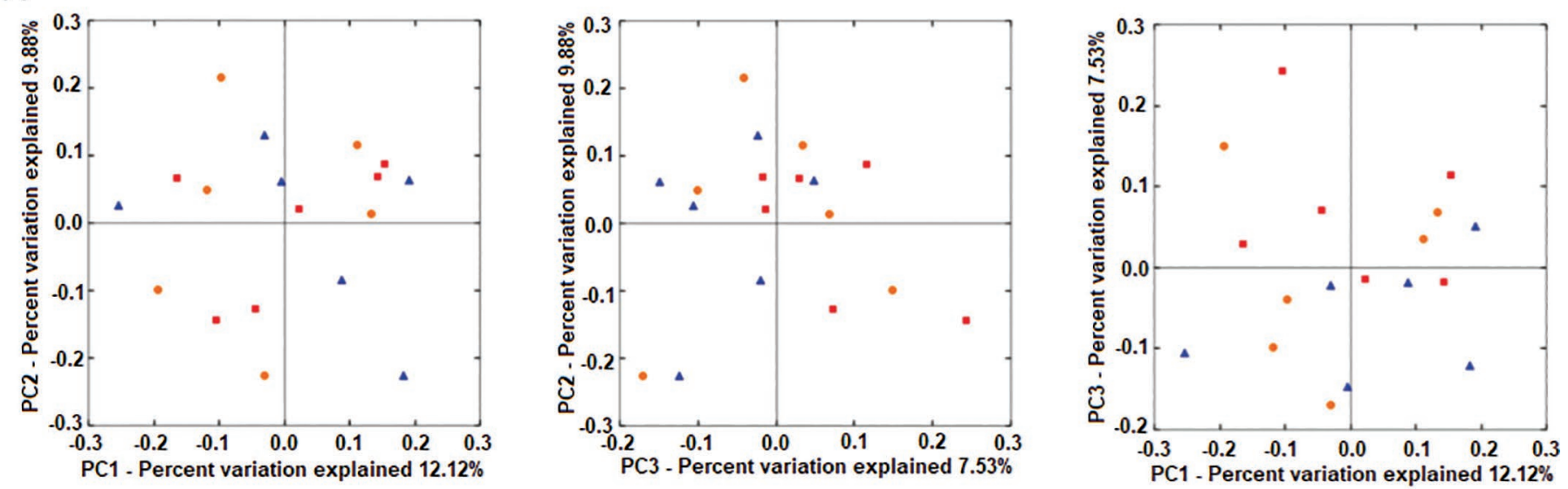

\section{B}
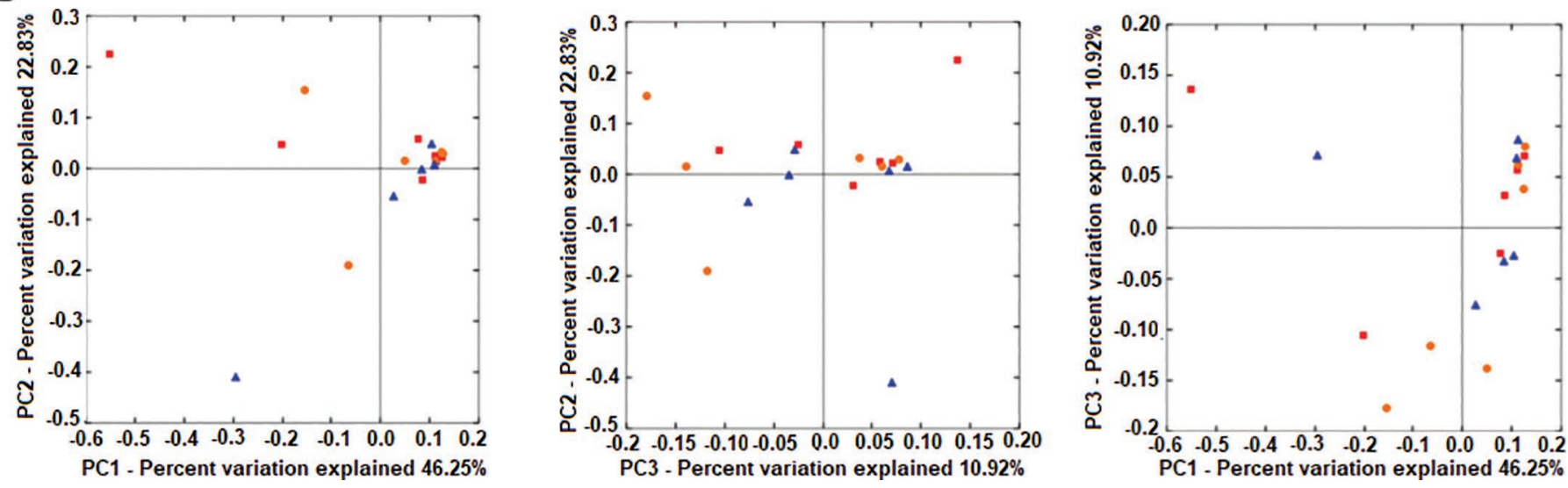

Figure 2. Principal coordinates (PC) analysis (PCoA) plots of bacterial profiles (at operational taxonomic unit level) based on (A) Jaccard's coefficient for binary data (presence of absence), and (B) Bray-Curtis similarity analysis (relative abundance) in milk samples from farm A. Color indicates mastitis history ( $\mathrm{red}=$ no mastitis, $\mathrm{SCC}<250,000$ cells $/ \mathrm{mL}$; blue $=$ mastitis, intermediate $\mathrm{SCC}$; orange $=$ mastitis, $\mathrm{SCC}$ $>1,000,000$ cells $/ \mathrm{mL}$ ). The values on each axis label represent the percentage of the total variance explained by that axis.

The PCoA plots of the bacterial profiles of the milk samples collected from farm B showed that a history of mastitis affected the clustering of bacterial relative abundance (Bray-Curtis) profile $(P=0.036$; Figure 4). In contrast, the clustering taking into account the presence or absence of the different OTU was not significantly affected depending on history of mastitis $(P$ $=0.087$; Figure 4 ). The heat map showing the relative abundance of the most abundant bacterial genera ( $\mathrm{x}$ axis) detected in milk samples from farm B indicated a higher degree of clustering compared with the results from farm A (Figure 5). The Spearman's rank correlation matrix of the major bacterial groups revealed weaker correlations compared with the results from farm A (Figure 5).

Bacterial diversity was notably greater when assessed by culture-independent methods than when assessed using culture media. The most abundant genera found by culture-dependent methods (Staphylococcus, Cory- nebacterium, Bacillus, Enterococcus, Pseudomonas, and Streptococcus) were also among the most abundant ones in the metataxonomic analysis. In contrast, some bacterial genera (Methylobacterium, Escherichia, Bifidobacterium, and Lactobacillus) that were abundant by culture-independent assessment could not be isolated by culturing.

\section{Immunological Analysis}

The frequency of detection of the 10 immune compounds analyzed in this study and (when detected) their concentration (medians and ranges) are shown in Table 3. All of the immunological factors could be detected in at least some of the milk samples, although their frequencies of detection were highly variable. Decorin was the only compound detected in all samples; IP-10, IFN- $\gamma$, and IL17-A were detected in more than $50 \%$ of the samples. We detected IP-10 in a higher number of 
A
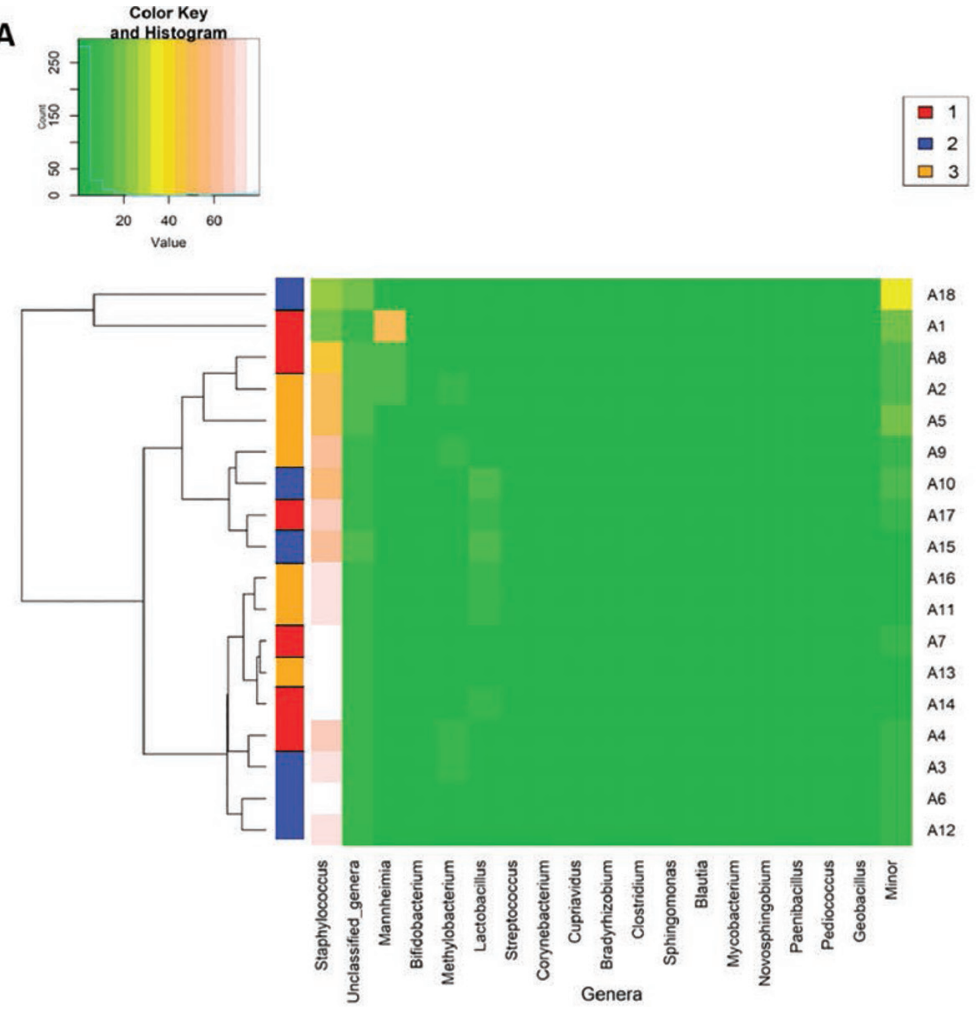

B

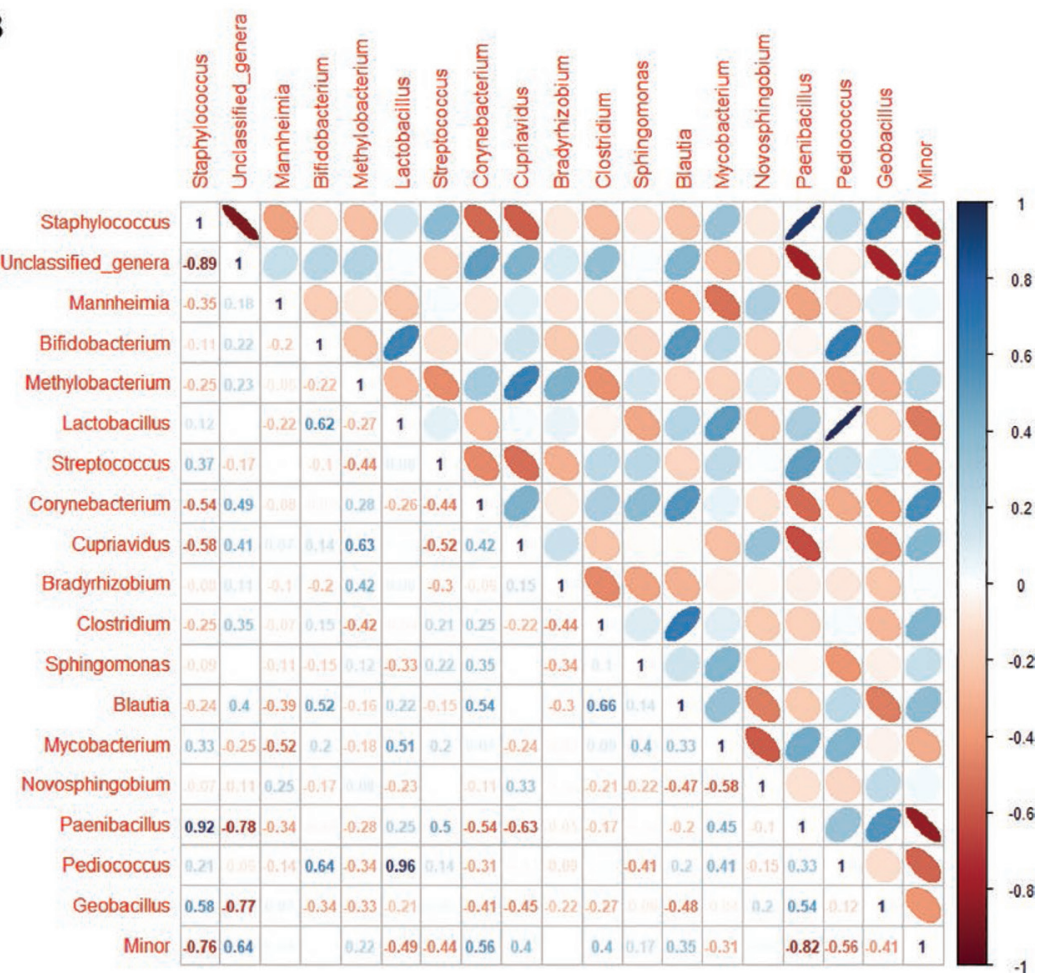

Figure 3. (A) Heat map showing the relative abundance of the most abundant bacterial genera (x-axis) detected in milk samples from farm A. The relative abundance of operational taxonomic units in each sample is indicated by the color of the scale, ranging from white (high relative abundance) to green (low relative abundance); see scale in left upper corner. Dendrogram linkages are based on the relative abundance of the genus in the sample, and we used "hclust" as the clustering algorithm. The column between the milk sample dendrogram and the relative abundance of bacterial genera indicates mastitis history (red = no mastitis, SCC $<250,000$ cells $/ \mathrm{mL}$; blue = mastitis, intermediate SCC; yellow $=$ mastitis, SCC >1,000,000 cells/mL). (B) Spearman's rank correlation matrix of the major bacterial genera in the same milk samples (present in $>50 \%$ of samples with a relative abundance $>0.1 \%$ ). Red represents a negative correlation, and blue represents a positive correlation. 
samples from ewes with a history of mastitis than in ewes without a history of mastitis $(P=0.005)$. In addition, the number of samples in which we detected IP-10 increased as SCC increased $(P=0.007)$. We detected CXCL9, IL-21, sFRP-3, and TNF- $\alpha$ in less than a half of the samples. We detected TNF- $\alpha$ more frequently in samples from ewes with the highest number of parities $(P=0.024)$. We detected IFN- $\gamma(P=0.044)$ and IL-21 $(P=0.005)$ more frequently (almost twice as often) among samples from farm B than among those from farm A. Finally, we detected VEGF-A and IL-8 in the smallest number of samples (17 and $14 \%$, respectively). We detected IL-8 only in samples from ewes with a history of mastitis and with an SCC $>1,000,000$ cells/ $\mathrm{mL}(P=0.001)$.

We found high interindividual variability in concentration of immune compounds. The compound detected at the highest concentration was IL-8 (median: 10,786 $\mathrm{pg} / \mathrm{mL}$; range: $2,058-16,985 \mathrm{pg} / \mathrm{mL}$ ); the compound detected at the lowest concentrations was (median: 7.25 $\mathrm{pg} / \mathrm{mL}$; range: $5.68-11.40 \mathrm{pg} / \mathrm{mL}$ ). When we compared groups (farm, number of parities, history of mastitis, SCC), we found significant differences only for concentration of sFRP-3 $(P=0.021)$, whose values increased globally with number of parities (medians: $149.56 \mathrm{pg} /$ $\mathrm{mL}$ for 2 to 3 parities, $305.98 \mathrm{pg} / \mathrm{mL}$ for 4 to 6 parities, $408.72 \mathrm{pg} / \mathrm{mL}$ for 7 to 9 parities; Figure 6 ). We also observed a trend between samples with a SCC $>1,000,000$ cells $/ \mathrm{mL}$ and the concentrations of IFN- $\gamma(P=0.053)$ and IP-10 $(P=0.059$; Figure 6$)$.

\section{DISCUSSION}

In this study, we examined the microbiota of ewe's milk using culture-dependent and -independent techniques to investigate the associations between 3 main variables: farm; history of mastitis or no mastitis; and number of parities. Although bacterial diversity was notably lower in the culture-based analyses, both approaches indicated that ewe's milk harbored a site-spe-
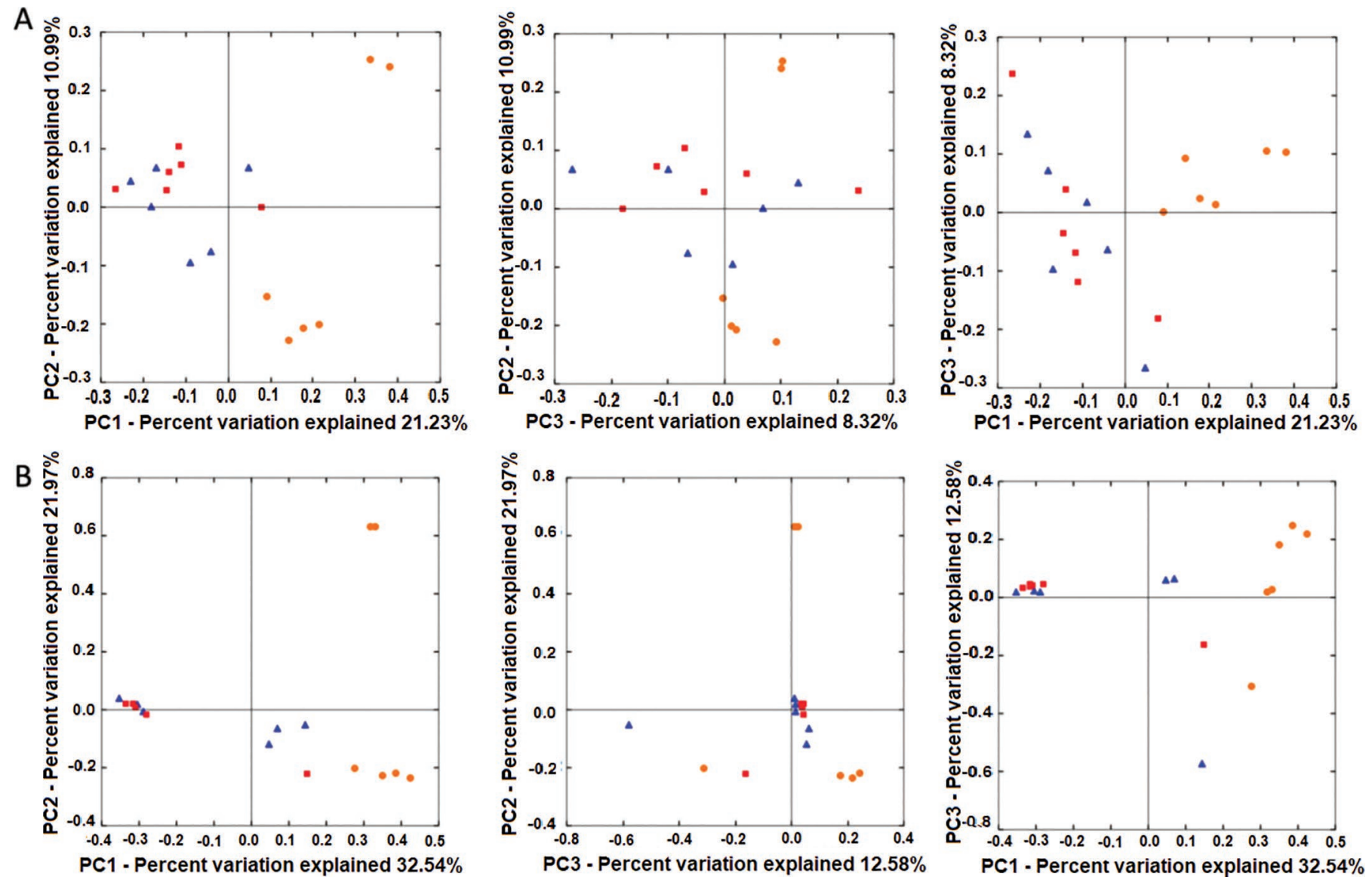

Figure 4. Principal coordinates (PC) analysis (PCoA) plots of bacterial profiles (at operational taxonomic unit level) based on (A) Jaccard's coefficient for binary data (presence/absence) and (B) Bray-Curtis similarity analysis (relative abundance) in milk samples from farm B. Color indicates mastitis history ( $\mathrm{red}=$ no mastitis, $\mathrm{SCC}<250,000$ cells $/ \mathrm{mL}$; blue $=$ mastitis, intermediate $\mathrm{SCC}$; orange $=$ mastitis, SCC $>1,000,000$ cells $/ \mathrm{mL}$ ). The values on each axis label represent the percentage of the total variance explained by that axis. 

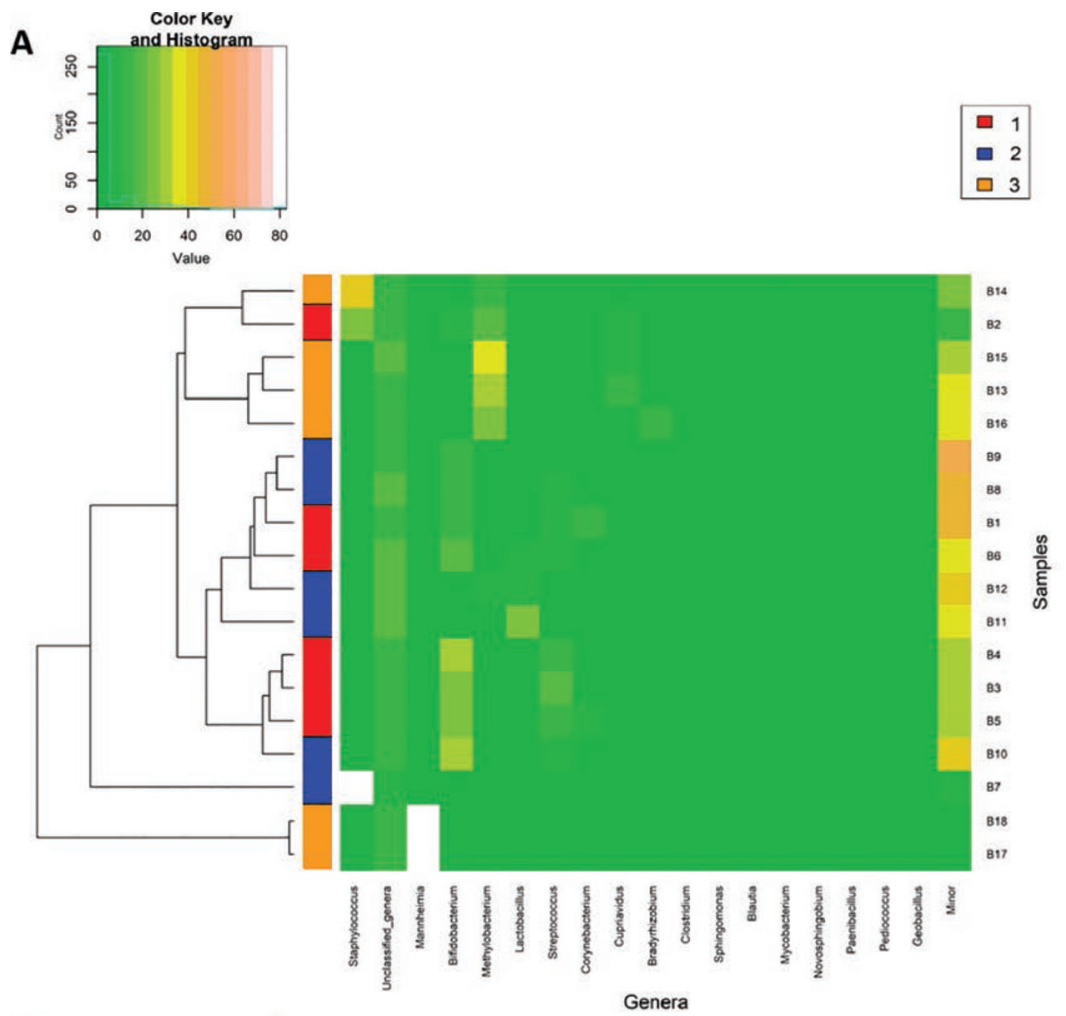

B

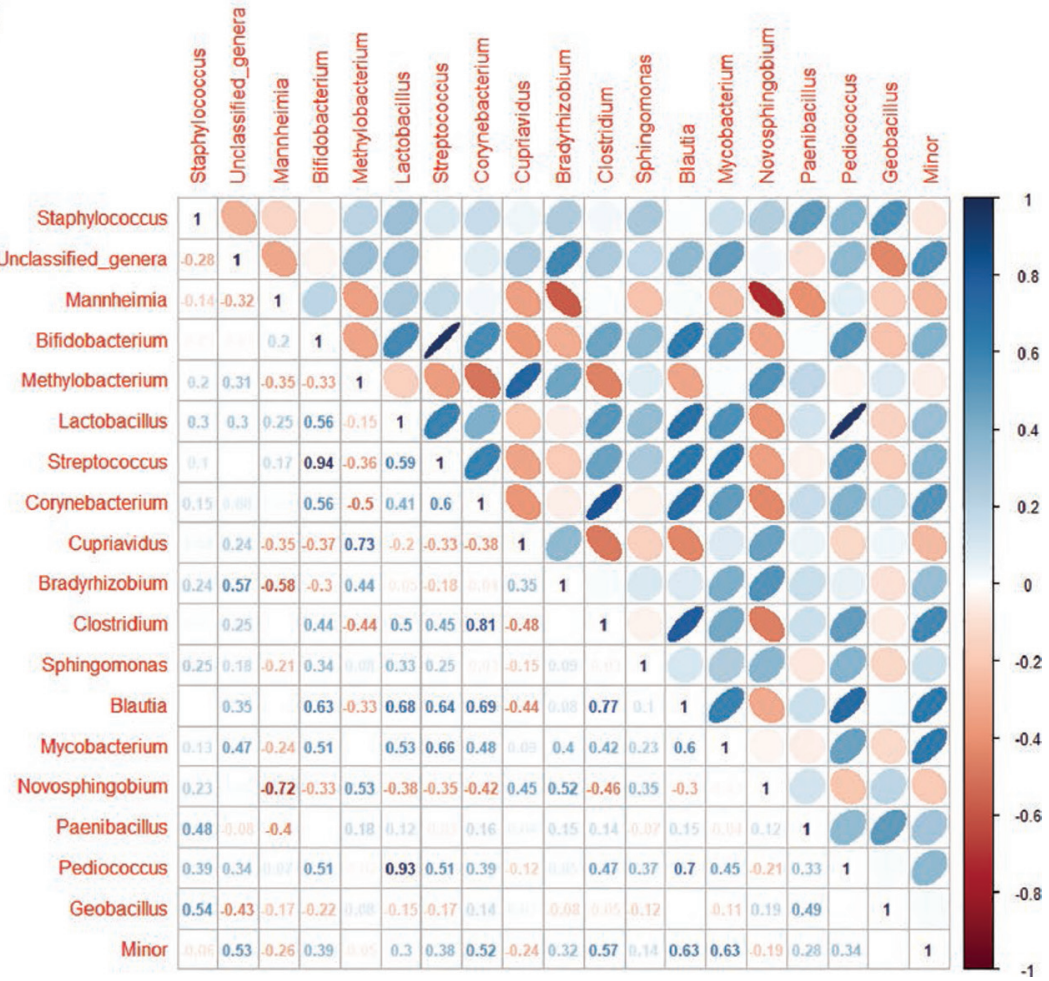

Figure 5. Heat map showing the relative abundance of the most abundant bacterial genera (x-axis) detected in milk samples from farm B. The relative abundance of operational taxonomic units in each sample is indicated by the color of the scale, ranging from white (high relative abundance) to green (low relative abundance); see scale in left upper corner. Dendrogram linkages are based on the relative abundance of the genus in the sample, and we used "hclust" as the clustering algorithm. The column between the milk sample dendrogram and the relative abundance of bacterial genera indicates mastitis history (red = no mastitis, $\mathrm{SCC}<250,000$ cells $/ \mathrm{mL}$; blue = mastitis, intermediate SCC; yellow $=$ mastitis, SCC >1,000,000 cells/mL). (B) Spearman's rank correlation matrix of the major bacterial genera in the same milk samples (present in $>50 \%$ of samples with a relative abundance $>0.1 \%$ ). Red represents a negative correlation, and blue represents a positive correlation. 
cific microbiota/microbiome, as previously suggested for other mammals (Oikonomou et al., 2014; Rainard, 2017; Derakhshani et al., 2018), and that the microbiological profile of ewe's milk is closely associated with the farm the animal lives on. We used only 3 culture media and 1 culture condition per medium for culturebased assessment of the milk microbiota. This approach significantly limited the bacteria that could be cultured and may have been responsible for the fact that some of the samples analyzed in this study had no detectable growth. This finding also highlighted the need for culturomics approaches focused on ruminant milk.

Staphylococcus epidermidis was the main species driving the difference observed between farm $\mathrm{A}$ (where it was the dominant species) and B (where it was not). Samples from farm B were characterized by a wide spectrum of other CNS (Staph. equorum, Staph. haemolyticus, Staph. hominis, Staph. schleiferi, Staph. warneri), detected mainly from animals with a history of mastitis. Some of these species have already been associated with subclinical intramammary infections in ruminants (Gonzalo et al., 2002; Gelasakis et al., 2015; Zigo et al., 2017).

Staphylococcus epidermidis can be isolated from the milk of healthy ewes and from the milk of ewes with mastitis (Fragkou et al., 2007). This species may switch from commensal to pathogen depending on the strain, the concentration, and the state of the host (Otto, 2009; Fernández et al., 2014). This species is dominant in the microbiota of human milk and its presence is a specific feature of the feces of healthy breastfed infants compared with those of formula-fed infants (Jiménez et al., 2008). Its predominance may help to explain the strong effect of human milk on the composition of the infant gut microbiota when infants are breastfed (Bäckhed et al., 2015) and why bacterial diversity grows when other foods are introduced (Favier et al., 2002). It has been proposed that the presence of Staph. epidermidis and other CNS may prevent infection by more damaging species, such as Staphylococcus aureus (Iwase et al., 2010; Park et al., 2011). However, Staph. epidermidis is a main cause of subacute mastitis in women (Delgado et al., 2009; Arroyo et al., 2010; Fernández et al., 2014) and in sheep (Gonzalo et al., 2002), a finding that has been confirmed in animal models (Thomsen et al., 1985). Similarly, Staph. epidermidis is the main cause of subclinical mastitis in sheep and can also cause clinical mastitis (Kiossis et al., 2007; Marogna et al., 2010; Cuccuru et al., 2011; Gelasakis et al., 2016). Other genera with species that could be involved in sheep mastitis, such as Streptococcus, Corynebacterium, Enterococcus, or Pseudomonas (Abdalhamed et al., 2018), were isolated only from the samples of animals with a history of mastitis in the present study.

The recent discovery that a species- and site-specific milk microbiota exists, and comparisons of the microbiota's composition in health and mastitis, have led to an emerging view that mastitis is an imbalance of the mammary microbiota rather than the action of a single pathogen (Fernández et al., 2014; Oikonomou et al., 2014; Patel et al., 2017; Derakhshani et al., 2018). However, other authors have disagreed with this idea and questioned whether a milk microbiota actually exists (Rainard, 2017). Although more studies involving more animals, breeds, and farms are needed to verify this hypothesis, the results of our study suggest that microbial signatures may help to detect herds and animals at higher risk of recurrent mastitis and may be used in the future as a tool for the selection of dairy sheep. It must be highlighted that, although none of the ewes had clinical signs of mastitis at the time of sampling, we cannot discount that at least some of those whose

Table 3. Relative frequency, median and interquartile range (IQR) of the concentration $(\mathrm{pg} / \mathrm{mL})$ of the immunological compounds in the milk samples

\begin{tabular}{lccc}
\hline Compound $^{1}$ & $\mathrm{~N}^{2}(\%)$ & Median $(\mathrm{IQR}), \mathrm{pg} / \mathrm{mL}$ & Range $(\mathrm{pg} / \mathrm{mL})$ \\
\hline CXCL9 & $14(39)$ & $267.18(134.25-489.90)$ & $79.03-910.40$ \\
Decorin & $36(100)$ & $255.46(164.53-320.23)$ & $33.66-320.23$ \\
IFNy & $20(55)$ & $58.90(34.71-223.08)$ & $21.82-576.62$ \\
IL-8 & $5(14)$ & $10,786(3,627-13,831)$ & $2,058-16,985$ \\
IL-17A & $21(58)$ & $135.99(57.05-455.13)$ & $38.16-2,867.50$ \\
IL-21 & $14(39)$ & $128.61(38.82-257.61)$ & $17.97-1,676.32$ \\
IP-10 & $18(50)$ & $162.23(45.95-414.80)$ & $17.56-1,209.73$ \\
sFRP3 & $14(39)$ & $323.5(186.7-417.5)$ & $124.3-2,181.8$ \\
TNF & $13(36)$ & $29.68(27.30-43.63)$ & $22.61-96.14$ \\
VEGFA & $6(17)$ & $7.25(5.68-11.40)$ & $4.97-31.03$ \\
\hline
\end{tabular}

${ }^{1}$ CXCL9 $=$ chemokine $(\mathrm{C}-\mathrm{X}-\mathrm{C}$ motif) ligand 9; IP-10 = interferon-inducible protein 10; SFRP3 = secreted frizzled-related protein $3, \mathrm{TNF} \alpha=$ tumor necrosis factor alpha; and VEGFA = vascular endothelial growth factor A.

${ }^{2}$ Number of samples in which the compound was detected (relative frequency of detection; total samples, $\mathrm{n}=$ $36)$. 

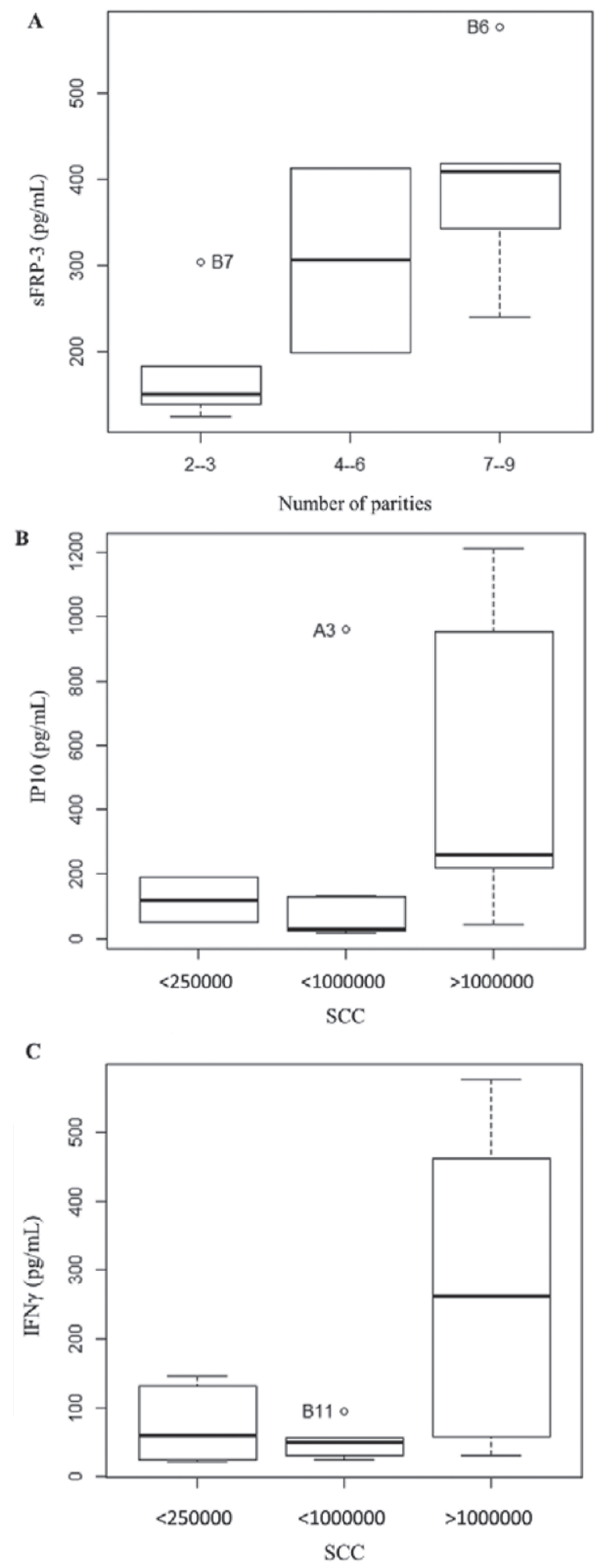

Figure 6. (A) Correlation between secreted frizzled-related protein 3 (sFRP-3) and number of parities; and trends observed between a SCC $>1,000,000$ cells $/ \mathrm{mL}$ and the values of $(\mathrm{B})$ interferon-inducible protein 10 (IP-10; $P=0.059)$ and $(\mathrm{C}) \operatorname{IFN} \gamma(P=0.053)$. The boxes represent the values of the interquartile ranges, with the median represented as a line. The whiskers are the minimum and maximum values, and the outliers are represented as dots. milk had SCC $>250,000$ cells $/ \mathrm{mL}$ just 15 to $30 \mathrm{~d}$ before sampling had subclinical mastitis. In fact, SCC of 200,000 to 400,000 cells/mL can be used as a cutoff value for subclinical mastitis in ewes (Ruegg, 2011).

The mean number of isolates per sample was 1.89 among the 36 samples cultured in this work. This value was below the criterion that is often used to consider milk microbial contamination (more than 2 types of bacteria in a single sample). However, 11 samples contained more than 2 bacterial isolates. Microbes can enter milk from different sources: for example, mammary, intestinal, or skin microbiota; air; feedstuffs; milk handling equipment; personnel (Metzger et al., 2018a,b). In fact, even when sample collection is done carefully using high standards of hygiene, there is a risk of contamination, especially when composite milk samples are collected, as was the case in the present study. Ideally, milk for metagenomics analysis should be collected via cisternal puncture; if it is collected through the teat canal, it impossible to know whether the true milk microbiome is being assessed, or a combination of the milk and teat microbiomes (Metzger et al., 2018a; Derakhshani et al., 2018). This factor should be taken in account in studies addressing the composition of milk microbiotas.

Sequencing samples with low biomass, such as milk, is also a challenging process that may result in skewed results due to the possible introduction of contaminants during DNA manipulation and sequencing. However, in the present study, we detected no amplification in the first PCR round from 2 blank controls that were submitted to the same extraction procedure as the biological samples.

The evidence of the close association between the microbiota and the immune system for the development and maintenance of host health has recently been demonstrated (Cremonesi et al., 2018). Among the 10 immune compounds assayed in this study, 3 (IL-8, IFN- $\gamma$, and IP-10) were related to a history of mastitis. Increases in milk concentrations of IL- 8 appear to be a feature of human and sheep subclinical mastitis (Winter and Colditz, 2002; Tuaillon et al., 2017; Hughes and Watson, 2018), and in the present study this immune factor was detected only in samples from ewes with a history of mastitis and from the group with the highest SCC. We also observed a positive correlation between samples with SCC $>1,000,000$ cells/mL and concentrations of $\operatorname{IFN}-\gamma(P=0.053)$ and IP-10 $(P=0.059)$. In human mastitis, inflammation is associated with higher levels of IFN- $\gamma$ and IP-10 (Tuaillon et al., 2017). We know that IFN- $\gamma$, or type II interferon, is critical for innate and adaptive immunity against bacterial infections (Schroder et al., 2004), and the chemokine IP-10 is secreted by several cell types in response to IFN- $\gamma$. 
Expression of IP-10 is seen in many inflammatory diseases, where it is thought to play an important role in recruiting or activating $\mathrm{T}$ cells at sites of tissue inflammation (Dufour et al., 2002). Although the availability of specific immunological assays for the detection and quantification of sheep immune compounds is scarce, our results suggest that these 3 compounds (particularly IL-8) could be used as a biomarker for the negative selection of mastitis-prone animals, particularly when $\mathrm{SCC}$ is very high $(>1,000,000 \mathrm{cfu} / \mathrm{mL})$. Again, more studies are needed to confirm their utility as tools for the control of mastitis in ewes.

\section{CONCLUSIONS}

In this study, the total bacterial counts of the samples from ewes with a history of mastitis were not statistically different from those of ewes without a history of mastitis. However, we did observe a positive trend between total bacterial count and SCC. The microbiome composition of the samples revealed significant differences by farm. A history of mastitis affected the clustering of the bacterial profiles from farm B but not from farm A. Of the immune compounds assayed in this study, 3 were related to a history of mastitis (IL-8, IFN- $\gamma$, and IP-10). These 3 compounds could be used as biomarkers for the negative selection of mastitisprone animals.

\section{ACKNOWLEDGMENTS}

This work has been funded by grant AGL2016-75476-R (Ministry of Economy and Competitiveness, Spain). We are grateful to the National Association of Selected Sheep Breeders of Manchega Breed (AGRAMA) for providing us with the samples.

\section{REFERENCES}

Abdalhamed, A. M., G. S. G. Zeedan, and H. A. A. A. Zeina. 2018. Isolation and identification of bacteria causing mastitis in small ruminants and their susceptibility to antibiotics, honey, essential oils, and plant extracts. Vet. World 11:355-362.

Akers, R. M., and S. C. Nickerson. 2011. Mastitis and its impact on structure and function in the ruminant mammary gland. J. Mammary Gland Biol. Neoplasia 16:275-289.

Arias, R., B. Oliete, M. Ramón, C. Arias, R. Gallego, V. Montoro, C. Gonzalo, and M. Pérez-Guzmán. 2012. Long-term study of environmental effects on test-day somatic cell count and milk yield in manchega sheep. Small Rumin. Res. 106:92-97.

Arroyo, R., V. Martin, A. Maldonado, E. Jimenez, L. Fernández, and J. M. Rodríguez. 2010. Treatment of infectious mastitis during lactation: Antibiotics versus oral administration of lactobacilli isolated from breast milk. Clin. Infect. Dis. 50:1551-1558.

Bäckhed, F., J. Roswall, Y. Peng, Q. Feng, H. Jia, P. KovatchevaDatchary, Y. Li, Y. Xia, H. Xie, H. Zhong, M. T. Khan, J. Zhang, J. Li, L. Xiao, J. Al-Aama, D. Zhang, Y. S. Lee, D. Kotowska, C. Colding, V. Tremaroli, Y. Yin, S. Bergman, X. Xu, L. Madsen,
K. Kristiansen, J. Dahlgren, and J. Wang. 2015. Dynamics and stabilization of the human gut microbiome during the first year of life. Cell Host Microbe 17:852.

Bonnefont, C. M., M. Toufeer, C. Caubet, E. Foulon, C. Tasca, M. R. Aurel, D. Bergonier, S. Boullier, C. Robert-Granié, G. Foucras, and R. Rupp. 2011. Transcriptomic analysis of milk somatic cells in mastitis resistant and susceptible sheep upon challenge with Staphylococcus epidermidis and Staphylococcus aureus. BMC Genomics. 12:208.

Caporaso, J. G., J. Kuczynski, J. Stombaugh, K. Bittinger, F. D. Bushman, E. K. Costello, N. Fierer, A. G. Peña, J. K. Goodrich, J. I. Gordon, G. A. Huttley, S. T. Kelley, D. Knights, J. E. Koenig, R. E. Ley, C. A. Lozupone, D. McDonald, B. D. Muegge, M. Pirrung, J. Reeder, J. R. Sevinsky, P. J. Turnbaugh, W. A. Walters, J. Widmann, T. Yatsunenko, J. Zaneveld, and R. Knight. 2010. QIIME allows analysis of high-throughput community sequencing data. Nat. Methods 7:335-336.

Contreras, G. A., and J. M. Rodriguez. 2011. Mastitis: Comparative etiology and epidemiology. J. Mammary Gland Biol. Neoplasia 16:339-356.

Cremonesi, P., C. Ceccarani, G. Curone, M. Severgnini, C. Pollera, V. Bronzo, F. Riva, M. F. Addis, J. Filipe, M. Amadori, E. Trevisi, D. Vigo, P. Moroni, and B. Castiglioni. 2018. Milk microbiome diversity and bacterial group prevalence in a comparison between healthy holstein frisian and rendena cows. PLoS One 13:e0205054.

Cuccuru, C., M. Meloni, E. Sala, L. Scaccabarozzi, C. Locatelli, P. Moroni, and V. Bronzo. 2011. Effects of intramammary infections on somatic cell score and milk yield in sarda sheep. N. Z. Vet. J. $59: 128-131$

Delgado, S., R. Arroyo, E. Jiménez, M. L. Marín, R. del Campo, L. Fernández, and J. M. Rodríguez. 2009. Staphylococcus epidermidis strains isolated from breast milk of women suffering infectious mastitis: Potential virulence traits and resistance to antibiotics. BMC Microbiol. 9:82.

Derakhshani, H., K. B. Fehr, S. Sepehri, D. Francoz, J. De Buck, H. W. Barkema, J. C. Plaizier, and E. Khafipour. 2018. Invited review: Microbiota of the bovine udder: Contributing factors and potential implications for udder health and mastitis susceptibility. J. Dairy Sci. 101:10605-10625.

Dufour, J. H., M. Dziejman, M. T. Liu, J. H. Leung, T. E. Lane, and A. D. Luster. 2002. IFN-gamma-inducible protein 10 (IP-10; CXCL10)-deficient mice reveal a role for IP-10 in effector T cell generation and trafficking. J. Immunol. 168:3195-3204.

EFSA. 2014. Scientific opinion on the welfare risks related to the farming of sheep for wool, meat and milk production. EFSA J. 12:3933

Ezzat Alnakip, M., M. Quintela-Baluja, K. Bohme, I. Fernandez-No, S. Caamano-Antelo, P. Calo-Mata, and J. Barros-Velazquez. 2014. The immunology of mammary gland of dairy ruminants between healthy and inflammatory conditions. J. Vet. Med. 2014:659801.

Favier, C. F., E. E. Vaughan, W. M. De Vos, and A. D. Akkermans. 2002. Molecular monitoring of succession of bacterial communities in human neonates. Appl. Environ. Microbiol. 68:219-226.

Fernández, L., R. Arroyo, I. Espinosa, M. Marín, E. Jiménez, and J. M. Rodríguez. 2014. Probiotics for human lactational mastitis. Benef. Microbes 5:169-183.

Fernández, L., S. Langa, V. Martin, A. Maldonado, E. Jimenez, R. Martin, and J. M. Rodriguez. 2013. The human milk microbiota: Origin and potential roles in health and disease. Pharmacol. Res. 69:1-10.

Fragkou, I. A., V. S. Mavrogianni, P. J. Cripps, D. A. Gougoulis, and G. C. Fthenakis. 2007. The bacterial flora in the teat duct of ewes can protect against and can cause mastitis. Vet. Res. 38:525-545.

Gelasakis, A. I., A. S. Angelidis, R. Giannakou, G. Filioussis, M. S. Kalamaki, and G. Arsenos. 2016. Bacterial subclinical mastitis and its effect on milk yield in low-input dairy goat herds. J. Dairy Sci. 99:3698-3708.

Gelasakis, A. I., V. S. Mavrogianni, I. G. Petridis, N. G. Vasileiou, and G. C. Fthenakis. 2015. Mastitis in sheep-The last 10 years and the future of research. Vet. Microbiol. 181:136-146.

Gonzalo, C., A. Ariznabarreta, J. A. Carriedo, and F. San Primitivo. 2002. Mammary pathogens and their relationship to somatic cell 
count and milk yield losses in dairy ewes. J. Dairy Sci. 85:14601467.

Hughes, K., and C. J. Watson. 2018. The mammary microenvironment in mastitis in humans, dairy ruminants, rabbits and rodents: A One Health focus. J. Mammary Gland Biol. Neoplasia 23:27-41.

Iwase, T., Y. Uehara, H. Shinji, A. Tajima, H. Seo, K. Takada, T. Agata, and Y. Mizunoe. 2010. Staphylococcus epidermidis Esp inhibits Staphylococcus aureus biofilm formation and nasal colonization. Nature 465:346-349.

Jiménez, E., J. de Andrés, M. Manrique, P. Pareja-Tobes, R. Tobes, J. F. Martínez-Blanch, F. M. Codoñer, D. Ramón, L. Fernández, and J. M. Rodríguez. 2015. Metagenomic analysis of milk of healthy and mastitis-suffering women. J. Hum. Lact. 31:406-415.

Jiménez, E., S. Delgado, A. Maldonado, R. Arroyo, M. Albújar, N. García, M. Jariod, L. Fernández, A. Gómez, and J. M. Rodríguez. 2008. Staphylococcus epidermidis: A differential trait of the fecal microbiota of breast-fed infants. BMC Microbiol. 8:143.

Kiossis, E., C. Brozos, E. Petridou, and C. Boscos. 2007. Program for the control of subclinical mastitis in dairy chios breed ewes during lactation. Small Rumin. Res. 73:194-199.

Klindworth, A., E. Pruesse, T. Schweer, J. Peplies, C. Quast, M. Horn, and F. O. Glöckner. 2013. Evaluation of general 16S ribosomal RNA gene PCR primers for classical and next-generation sequencing-based diversity studies. Nucleic Acids Res. 41:e1.

Lam, T. J., Y. H. Schukken, J. H. van Vliet, F. J. Grommers, M. J. Tielen, and A. Brand. 1997. Effect of natural infection with minor pathogens on susceptibility to natural infection with major pathogens in the bovine mammary gland. Am. J. Vet. Res. 58:17-22.

Linde, C. O. Holmberg, and G. Astrom. 1980. The interference between coagulase negative staphylococci and Corynebacterium bovis and the common udder pathogens in the lactating cow. Nord. Vet. Med. 32:552-558.

Sam Ma, Z., Q. Guan, C. Ye, C. Zhang, J. A. Foster, and L. J. Forney. 2015. Network analysis suggests a potentially 'evil' alliance of opportunistic pathogens inhibited by a cooperative network in human milk bacterial communities. Sci. Rep. 5:8275.

Marogna, G., S. Rolesu, S. Lollai, S. Tola, and G. Leori. 2010. Clinical findings in sheep farms affected by recurrent bacterial mastitis. Small Rumin. Res. 88:119-125.

Matthews, K. R., R. J. Harmon, and B. A. Smith. 1990. Protective effect of Staphylococcus chromogenes infection against Staphylococcus aureus infection in the lactating bovine mammary gland. J. Dairy Sci. 73:3457-3462.

Metzger, S. A., L. L. Hernandez, J. H. Skarlupka, G. Suen, T. M. Walker, and P. L. Ruegg. 2018a. Influence of sampling technique and bedding type on the milk microbiota: Results of a pilot study. J. Dairy Sci. 101:6346-6356.

Metzger, S. A., L. L. Hernandez, G. Suen, and P. L. Ruegg. 2018b, Understanding the milk microbiota. Vet. Clin. North Am. Food Anim. Pract. 34:427-438.

Oikonomou, G., M. L. Bicalho, E. Meira, R. E. Rossi, C. Foditsch, V. S. Machado, A. G. V. Teixeira, C. Santisteban, Y. H. Schukken, and R. C. Bicalho. 2014. Microbiota of cow's milk; distinguishing healthy, sub-clinically and clinically diseased quarters. PLoS One 9:e85904

Otto, M. 2009. Staphylococcus epidermidis - The 'accidental' pathogen. Nat. Rev. Microbiol. 7:555

Pang, M., X. Xie, H. Bao, L. Sun, T. He, H. Zhao, Y. Zhou, L. Zhang, H. Zhang, and R. Wei. 2018. Insights into the bovine milk microbiota in dairy farms with different incidence rates of subclinical mastitis. Front. Microbiol. 9:2379.

Park, B., T. Iwase, and G. Y. Liu. 2011. Intranasal application of $S$. epidermidis prevents colonization by methicillin-resistant Staphylococcus aureus in mice. PLoS One 6:e25880.

Patel, S. H., Y. H. Vaidya, R. J. Patel, R. J. Pandit, C. G. Joshi, and A. P. Kunjadiya. 2017. Culture independent assessment of human milk microbial community in lactational mastitis. Sci. Rep. 7:7804

Qiao, J., L. Kwok, J. Zhang, P. Gao, Y. Zheng, Z. Guo, Q. Hou, D. Huo, W. Huang, and H. Zhang. 2015. Reduction of lactobacillus in the milks of cows with subclinical mastitis. Benef. Microbes 6:485-490.

Rainard, P. 2017. Mammary microbiota of dairy ruminants: Fact or fiction? Vet. Res. 48:25.

Ruegg, L. 2011. Mastitis in small ruminants. Pages 1-26 in Annual Conf. Am. Assoc. Bovine Practitioners, Small Ruminant Session, St. Louis, MO. Am. Assoc. Bovine Practitioners, Ashland, OH.

Schroder, K., P. J. Hertzog, T. Ravasi, and D. A. Hume. 2004 Interferon- $\gamma$ : An overview of signals, mechanisms and functions. J. Leukoc. Biol. 75:163-189.

Sordillo, L. M., and K. L. Streicher. 2002. Mammary gland immunity and mastitis susceptibility. J. Mammary Gland Biol. Neoplasia $7: 135-146$.

Thomsen, A. C., S. C. Mogensen, and F. Løve Jepsen. 1985. Experimental mastitis in mice induced by coagulase-negative staphylococci isolated from cases of mastitis in nursing women. Acta Obstet. Gynecol. Scand. 64:163-166.

Tuaillon, E., J. Viljoen, P. Dujols, G. Cambonie, P. Rubbo, N. Nagot, R. M. Bland, S. Badiou, M. Newell, and P. Van de Perre. 2017. Subclinical mastitis occurs frequently in association with dramatic changes in inflammatory/anti-inflammatory breast milk components. Pediatr. Res. 81:556.

Winter, P., and I. Colditz. 2002. Immunological responses of the lactating ovine udder following experimental challenge with Staphylococcus epidermidis. Vet. Immunol. Immunopathol. 89:57-65.

Zakrzewski, M., C. Proietti, J. J. Ellis, S. Hasan, M. Brion, B. Berger, and L. Krause. 2017. Calypso: A user-friendly web-server for mining and visualizing microbiome-environment interactions. Bioinformatics 33:782-783.

Zigo, F., M. Vasil', J. Elečko, M. Zigová, and Z. Farkašová. 2017. Mastitis pathogens isolated from samples of milk in dairy cows and their resistance against antimicrobial agents. J. Food Sci. Eng. $7: 110-113$. 